LBNL - 60012

\title{
Seismicity Precursors of the M6.0 2004 Parkfield and M7.0 1989 Loma Prieta Earthquakes
}

\author{
Valeri A. Korneev \\ Earth Sciences Division, Lawrence Berkeley National Laboratory, Berkeley, California
}

April 2006

This work was done at the Center for Computational Seismology (CCS) at Lawrence Berkeley National Laboratory, which is operated by the University of California for the U.S. Department of Energy (DOE) under Contract No. DE-AC03-76SF00098. 


\title{
Seismicity Precursors of the M6.0 2004 Parkfield and M7.0 1989 Loma Prieta Earthquakes
}

\author{
Valeri Korneev \\ Lawrence Berkeley National Laboratory, Berkeley, California \\ VAKorneev@lbl.gov
}

\begin{abstract}
The M6.0 2004 Parkfield and M7.0 1989 Loma Prieta strike-slip earthquakes—on the San Andreas Fault (SAF) - were preceded by seismicity peaks occurring several months prior to the main events. Earthquakes directly within the SAF zone were intentionally excluded from the analysis because they manifest stress-release processes rather than stress accumulation. The observed increase in seismicity is interpreted as a signature of the increasing stress level in the surrounding crust, whereas the peaks and the subsequent decrease in seismicity are attributed to damage-induced softening processes. Furthermore, in both cases there is a distinctive zone of low seismic activity that surrounds the epicentral region in the pre-event period. The increase of seismicity in the crust surrounding a potential future event and the development of a low-seismicity epicentral zone can be regarded as promising precursory information that could help signal the arrival of large earthquakes. The Gutenberg-Richter relationship (GRR) should allow extrapolation of seismicity changes down to seismic noise level magnitudes. This hypothesis is verified by comparison of seismic noise at $80 \mathrm{~Hz}$ with the Parkfield M4 1993-1994 series, where noise peaks 5 months before the series to about twice the background level.
\end{abstract}

\section{Introduction}

The town of Parkfield, located on the San Andreas Fault (SAF) in central California, has been the site of intensive, multidisciplinary earthquake studies since the 1970s. Moderate-sized earthquakes of about magnitude 6 (M6.0) have occurred on the Parkfield section of the SAF at fairly regular intervals-in 1857, 1881, 1901, 1922, 1934, and 1966 (Bakun and McEvilly, 1979). The 1857 event was a foreshock of the great Fort Tejon M7.9 earthquake, which produced a rupture along the fault at least $290 \mathrm{~km}$ in length from Parkfield to the southeast (Meltzner and Wald, 1999)-and the probability 
that another moderate-sized Parkfield earthquake might occur as a foreshock to another Fort Tejon-type event remains high.

The goal of research in the Parkfield area has been to observe the fault and surrounding crust, at close range and at high resolution, before, during, and after a characteristic M6 earthquake, so as to better understand the earthquake process and to provide a scientific basis for earthquake prediction and hazard assessment. Recognizing this hazard, and the regular periodicity of recurring events near Parkfield, the U.S. Geological Survey (USGS) and the State of California began a comprehensive, long-term Parkfield Earthquake Prediction Project in 1985 (Bakun and Lindh, 1985). More than 10,000 earthquakes have been recorded since 1970 in the magnitude range $0<M<5$. The long anticipated M6.0 event finally occurred on September 28, 2004. Langbein et al. (2005) issued a preliminary report indicating that no immediate precursory phenomena were observed, which was confirmed by Bakun et al, (2005).

There is currently little optimism in the scientific community about the possibility of earthquake prediction (Geller, 1997; http://earthquake.usgs.gov hazards/ prediction.html; Geller, et al., 1996). Recent discussions in Nature (http://www.nature.com/nature/debates/earthquake/index.html) include such statements as: "[W]e do not have a method for making short-term predictions"; "[T]here is a bleak future for individual earthquake prediction"; and "[T]here is no prospect of deterministic earthquake prediction in the foreseeable future". While it is not the intention of this paper to give an overview of current earthquake prediction methods, the author notes that most methods (e.g., Bowman and Sammis, 2004) seek changes in coefficients of the Gutenberg-Richter relationship (GRR) $\log N=a-b M$, which relates the number of earthquakes $(N)$ greater than magnitude $M$ in some region to the magnitude itself. The GRR reflects the behavior of seismicity over periods of time sufficiently long enough to collect reliable statistics for a wide range of magnitudes.

However, using the GRR as a basis for prediction methods has several disadvantages. First, the relatively rare occurrence of large magnitude events means that there is great uncertainty in the predicted probability of a large event. Second, applications of this relationship provide no information concerning the location of an event within a catalogued region. Third, and finally, current earthquake-generating models show little or no direct relationship between changes in the GRR coefficients (a and b) and characteristic earthquake occurrences. The catastrophic events similar to 
M7.9 Fort Tejon (Langbein et al., 2005) and M7.7 1906 San Francisco (Wald et al., 1999) have an average slip of about $4 \mathrm{~m}$ (Wald et al, 1993), which translates to an average recurrence time interval of every 100-200 years. This evaluation assumes approximately 2-3 cm/yr of average tectonic plate displacement by SAF and also accounts for some incomplete release of accumulated strain for those events. With catastrophic events occurring so rarely, even moderate uncertainty in prediction makes it unrealistic to use GRR-derived statistics for disaster-related warnings. Moreover, predictions expressed in terms of probabilities are inappropriate for rare earthquake occurrences, since definitions of probability are based on statistical limits of multiply occurring events. Practically applicable prediction methods need to be based on causal approaches.

In this paper, a selective seismicity analysis is used in which only events having a direct relationship with strain-buildup processes are included. The idea of selectiveness is partially based on the results of a Vibroseis monitoring experiment in which seismic waves repeatedly illuminated the epicentral region of the expected M6 event at Parkfield from June 1987 to November 1996. Data collected by the borehole network were examined for evidence of changes associated with the nucleation process of the anticipated M6 earthquake at Parkfield (Karageorgi et al., 1992, 1996; Korneev et al., 2000, Korneev and Nadeau, 2004). These investigations reported significant travel-time changes for paths crossing the fault zone in the locked southeast part of SAF, while in the northwest (creeping) part of the SAF, no changes were observed. This result suggests that little or no information about stress accumulation in the SAF can be gathered from the seismicity of the SAF's creeping part, where a weak fault steadily releases small stress changes and the seismicity mostly represents a stationary random process. Indeed, the weak creeping faults can be modeled as large-scale fractures having very low friction and the capability to immediately discharge any applied shear stresses. The stress-strain conditions on both sides of such fractures generally stay unchanged, with just small fluctuations and no dependence on the regional stress buildup. At the same time, the seismicity associated with weak faults makes a dominant contribution to regional event statistics, overshadowing the seismicity directly related to regional stress accumulation. Therefore, all events with hypocenters within the active fault zone are excluded from the results shown in this paper. The transition zone between the locked and creeping parts of SAF is a northwesterly dipping structure, oriented at approximately $45^{\circ}$ and extending for about $5 \mathrm{~km}$ along the fault (Korneev et 
al., 2003, Figure 8).

Not all earthquakes can be recorded by a seismic recording network. Typically, if most stations within the network detect an event within the same interval of several seconds, the network is triggered and the event is recorded, located, and made available in catalogues. For the Parkfield area, all events above magnitude 1.5 are likely recorded, as reflected in the statistics of regional seismicity providing a good fit to the GRR (Figure 1). However, not all smaller-magnitude events are detected, because they have low amplitudes relative to seismic noise. Although this suggests that recorded events of magnitude $<1.5$ cannot be used for GRR statistics, such events nonetheless can give rise to a strong precursory signature (Korneev, 2005), as demonstrated below.

\section{Results}

Parkfield M6, 2004

The U.S. Geological Survey catalog was initially used to analyze the spatial and temporal distribution of Parkfield-area events from 1968 to the main shock of the M6 2004, which occurred on September 28 (Figure 2). In March 2006 the data were reprocessed after incorporating events relocated by double-differences (DD) method (Thurber et al., 2006), brining minor corrections to the results. The total number of events occurring per month was computed and analyzed. During this 36 years period of observation, four distinct peaks of seismicity are visible in the data (Figure 3). The first three peaks correspond to the aftershock series following the M5.5 1975 Parkfield, M6.5 1983 Coalinga, and a series of four M4 1992-1994 Parkfield events. The final rise in seismicity begins in 2000, attains its peak in December 2003, and then falls to below the average level before the M6 2004 event. To eliminate the influence of aftershock and creeping seismicity, all seismic events within a $6 \mathrm{~km}$ and outside of $15 \mathrm{~km}$ corridors around the central SAF zone were excluded from the data observed in the $35 \mathrm{~km} \times 50$ $\mathrm{km}$ area around the epicenter (as shown in Figure 4). The resulting seismicity is shown in Figure 5a and b. Except for the two sharp peaks in 1970 (M3.9 Parkfield aftershocks) and 1983 (M6.5 Coalinga aftershocks), the only other increase in seismicity begins in the middle of 2002 and reaches its maximum in May 2004. There are visible cyclic bursts of seismicity that occur at decreasing intervals. Expansion of the analysis area beyond the chosen size produces the same effect, but the results become increasingly 
contaminated by aftershock events of M6.5 1983 Coalinga and M6.5 2003 San Simeon earthquakes. Computations show that the observed pre-event peaks are not very sensitive to the elimination corridor width until it decreases to about $3 \mathrm{~km}$, at which time the creeping SAF events become statistically dominant.

Further elimination of all events with magnitudes greater than 1 produces even more distinctive results (Figure 5c, d). The peak in such "microseimicity" occurs about 6 months prior to the main M6 2004 event, and is 8 times greater than the background level of roughly two recorded events per 10 days. Following the peak, there is a steady decrease in activity up to the time of the main event. Prior to the peak, no distinctive features can be seen in this microseismicity. In the year preceding the main event, the epicenters of the microseismicity are mostly concentrated along the delineation zone between the creeping and locked parts of the SAF (Figure 6). Also during this period, an area approximately $30 \mathrm{~km}$ in diameter surrounding the future M6 2004 epicenter contains no events. This no-activity area lies mostly on the southwest side of the SAF.

To better understand the spatial and temporal characteristics of the observed peaks, a seismicity count was performed, using a scan-stripe oriented in southwest-northeast direction (Figure 7) and crossing the SAF along the creeping-locked delineation line shown in Figure 2. This scan-stripe extends up to $80 \mathrm{~km}$ offset from the SAF in the southwest direction, where it crosses the epicentral region of the M6.5 San Simeon 2003; on the other side it has a $60 \mathrm{~km}$ offset in the southwest direction, where it crosses the epicentral region of the M6.5 Coalinga 1983 event. The seismicity history starting from 1968 to 2005 for the $4 \mathrm{~km}$ by $20 \mathrm{~km}$ rectangle was computed for a $4 \mathrm{~km}$ interval in the southeast-northwest direction, ensuring that no event is counted more than once. The results are shown in Figure 8. The distinctive strong burst of out-of-fault seismicity precedes the M6.0 Parkfield earthquake by several months (upper circled areas).

\section{Loma Prieta M7.0 1989}

A similar analysis was applied to the events preceding the M7.0 1989 Loma Prieta earthquake, which caused substantial damage in the San Francisco Bay Area region. The area to the west of the epicenter was chosen for seismicity study because it does not contain as many active faults as other areas adjacent to the epicenter. Figure $9 \mathrm{a}$ shows the seismicity history for the 25 years of observation before the event. In the two months prior to the event, (Figures $9 \mathrm{c}$ and $\mathrm{d}$ ), seismicity increased to approximately 
eight times the base level of about 6 events per month, and then decreased over the following two months. Analysis of the low magnitude $(<1)$ seismicity yielded the same trend, although there were not enough events for statistically significant results. Similarly to the Parkfield case, in the last year before the earthquake, a low-seismicity area appeared around the future rupture (Figure $7 \mathrm{~b}$ ). Existence of this area was shown in Reasenberg and Simpson, (1992) after comparing long periods of seismicity before and after the earthquake.

Space-temporal seismicity analysis (Figure 10) for the M7 Loma Prieta area was done in the same manner as for the Parkfield M6 event (Figure 8), with the geometry of the scan-stripe shown in the upper part of Figure 7. The offset of scanning for the $4 \mathrm{~km}$ by $20 \mathrm{~km}$ rectangle has values in the $-45-80 \mathrm{~km}$ range, measured from the SAF at $4 \mathrm{~km}$ intervals. Seismicity growth preceding the M7 Loma Prieta event is shown in the red circle. The M7 event was preceded by two (M5.3 1988 and M5.4 1989) Lake Elsman events. Note that while M5.3 1988 showed only a slight rise in seismicity (Figure 7d); the M5.4 1989 was preceded by distinctive seismicity outbursts contributing to the pre- M7 peak. This pre-event seismicity pattern is similar to the pattern observed for the M6 Parkfield earthquake in Figure 8. Note that the Lake Elsman events do not belong to the creeping sections of the faults, and therefore they are incorporated in the seismicity count.

\section{Seismic noise information}

According to the GRR, seismicity should exponentially increase in lower magnitudes. However, current instrumentation capabilities do not allow robust detection and location of all events, usually limiting the lowest detectable magnitude to 0 . Numerous events with negative magnitudes therefore stay below the seismic-stationnetwork resolution. The typical seismic station network has an average spacing of about $10 \mathrm{~km}$ and operates in a trigger fashion: when a certain threshold number of stations record an event it counts as a triggered event and gets stored in a database. While all large-amplitude events trigger the network, events with small amplitude have less

chance to be recorded because of the lower signal-to-noise ratio. Also, small-magnitude events have higher cyclic frequency content, and therefore their waves are more attenuated. As a result, the number of detected "very small" magnitude events is lower 
compared to the seismicity of high-magnitude events which reveals itself as a violation of the GRR and cannot be used for $a$ - and $b$-constants evaluation. For example, in Figure 1 shown cumulative seismicity recorded before M6 2004 Parkfield event for the area from Figure 2. Violation of the GGR is visible for the magnitudes below 1.5. Thus the direct application of GRR and monitoring of its constants is restricted by poor statistics of the rarely occurring large-magnitude events and by resolution limitations in the detection of small magnitude events. To increase the resolution we need much denser networks whose stations are located in boreholes (as it is now for HRSN). But this is currently a rather expensive solution.

A different approach for seismicity monitoring can be based on the statistical connection between events of different magnitudes (given by the GRR), and leads to a hypothesis about the direct correspondence between seismic noise level and seismicity for magnitudes falling in the detectable region $(M>-1)$. Seismicity changes for detectable (rare) events are likely to be accompanied by similar changes for undetectable micro-events which comprise background seismic noise. Small magnitude seismicity $(\mathrm{M}<-1)$ has higher frequencies and therefore has a local character, due to the high attenuation for these frequencies. This hypothesis was tested using Parkfield data for MMNB borehole station of the HRSN, which was recorded from the same microearthquake cluster over a 10 year interval. This station was chosen because it is located in the vicinity of the SAF locked-creeping transition zone where in 1993-1994 series of M4 events occurred and thus likely produced local stress changes. Noise records were taken from the initial 1.5-second intervals of traces that precede the first arrival, and the average noise amplitude was computed in the $80-100 \mathrm{~Hz}$ range. Assuming 3D distribution of seismic noise sources, the maximum contribution distance $r$ can be evaluated from following formula

$$
r=\frac{Q \mathrm{v}}{2 \pi f}
$$

where $Q$ is a quality factor, $v$ is velocity, and $f$ is frequency. For $f=100 \mathrm{~Hz}, Q=200, v=3$ $\mathrm{km} / \mathrm{s}$, the radius is approximately equal to $1 \mathrm{~km}$. Thus, at high frequencies, noise measurements cover volumes of just a few kilometers in dimension and have a local character. Figure 11 shows a comparison of noise amplitudes with seismicity in the 5 $\mathrm{km}$ vicinity of MMNB station at Parkfield. As seen from Figure 11, the noise energy rises by about two times several months before the seismicity peak. 


\section{Discussion}

The out-of-fault-zone microseismicity patterns of the two events studied here are quite similar, consisting of a sharp seismicity increase that reaches its maximum several months prior to the main event and then decreases to background seismicity levels by the time the main event occurs. The pre- Parkfield M6 seismicity peaks forms a unique pattern for 38 years of observation time, and they occur 6-2 months before the earthquake. This microseismicity clusters at $15-20 \mathrm{~km}$ offset from the fault and then migrates closer to the SAF, peaking two months before the main event at 5-10 km offset. Note, that off-fault seismicity activity usually followed by in-fault seismicity rise, which likely indicates the accelerated fault creep, which reduces stress in the surrounding crust. There is an indication of some crosstalk between the 2003 San Simeon event and the pre-M6 Parkfield seismicity peak, although they are separated by 3-4 months. The shape of the San Simeon aftershock series nicely reveal the Omori law decay. There is also a visible increase in seismic activity within the SAF 1-2 months before the San Simeon earthquake. This implies that the pre-event seismicity rise in Park field is unlikely to be part of the San Simeon aftershock series, and rather represents a different process, although some weak stress interaction between the Parkfield and San Simeon regions might be possible. Note that the pre-M4.2 2002 seismicity peak in the SAF area occurs 4 months before the event and has a pattern similar to that of the M6 event (Figure 5b). For the Loma Prieta earthquake, the same pattern is observed: Seismic activity starts at a $15 \mathrm{~km}$ offset from the SAF 5 months before the event, and then moves closer to the SAF, peaking 2 months before at a $5 \mathrm{~km}$ offset from the SAF. This similarity suggests the scalability of the observed precursory seismicity phenomena to events of different magnitudes.

Seismicity peaks occurring in 1970 and in 1983 observed for the Parkfield area have distinctly different spatial and temporal character in comparison with the pre- M6 event seismicity. The1983 peak is caused by aftershocks of the M6.5 Coalinga earthquake and composed of the events located on the North-East side of the SAF. The 1970 swarm occurred within 4 hours interval at February 231970 in the compact 4 sq miles area at Cholame Hills on the South-West side of the SAF. Development of the observed precursors was at least several months long, it had a cyclic character and it was observed on both sides of the SAF (Figure 8). 
The author proposes an explanation for the observed seismicity precursors-with the understanding that such an explanation requires further, intensive study.

Increased seismicity in rocks under increasing stress is a well-known laboratory observation $^{1}$ (e.g., Lei et al., 2000a,b; Lockner et al., 1992). Under increasing shear strain, the seismicity of an initially intact rock sample grows throughout the so-called "strain-hardening regime." This seismicity reaches a peak, after which the seismicity rate drops as the rock sample enters a "softening" stage associated with strain localization and failure along a band of accumulated damage (Lei et al., 2004; Sable et al., 1996). Note that the constant stress load experiments do not produce a visible decrease in seismicity before rock failure, whereas constant strain-rate-load experiments produce such peaks (as supported by laboratory data [Lei et al., 2005] and numerical modeling [Tham, 2001]). In the presence of pre-existing faults in nature (like the SAF), a slightly different scenario is plausible. It is well known that most earthquakes occur on existing faults and that fault-zone rocks have less strength than the surrounding crust. For an increasing strain load, the stress-strain relationships start behaving nonlinearly (Sholtz, 1990) and, after reaching a maximum stress value, enter a softening (or dilatancy) regime, characterized by the development of multiple fractures and reduction of rock stiffness. This process eventually progresses to rock failure (earthquake). During this process, the stronger out-of-fault rock experiences the same stress load, but does not reach a nonlinear regime (Figure 12). The fault's stress-strain curve maximum provides a corresponding maximum for the stress in the surrounding crust, which in its turn creates a peak in seismicity; according to the empirical fourth-power relationship between stress and seismicity (Dunegan, 1999). The fault-zone rocks occupy relatively small volumes because they are aligned to the fault planes having widths several hundred meters or less. At the same time, the out-of-fault rocks have much larger volumes, by virtue of being essentially $3 \mathrm{D}$ structures that provide better statistics for event count. This simplistic, but illustrative mechanism can be further quantified by applying more complex models, such as the following.

As strain builds through tectonic loading, it appears that at sufficiently large stress levels, the crust enters a strain-hardening regime in which the crust surrounding the fault begins to microcrack, as manifested through the increased level of seismicity observed

\footnotetext{
${ }^{11}$ Event count in laboratory rock-testing experiments is usually called acoustic emission. In seismology, the term seismicity is traditionally used for the correspondent phenomena. As follows from the results of this paper, both terms are equally suitable in descriptions of the observed precursory increase of micro-events frequency.
} 
(for example in Figure 5). However, as seismicity intensifies, and strain continues to build, slip velocities on portions of the fault may begin to increase. The increased seismicity may act on the fault by (for example) changing the rate-and-state parameters (Melosh, 1979) controlling the slip rate on the fault (Ruina, 1983; Dieterich, 1994). Acceleration of the SAF prior to 2004 M4 event manifests itself in average fault seismicity increase starting being visible about 4 years before the event (Figure 3 ).

Specifically, the state variable used to characterize the average age of contact asperities in the rate-and-state formalism is likely to decrease along the fault owing to vibration. Accordingly, the laws of rate-and-state friction (Dieterich, 1994) predict that there will be an increase in slip rate that will both decrease the strain and seismic activity in the surrounding crust, and decrease the length of time before the next high-velocity event (earthquake) occurs. The oscillation of pre-event seismicity in the Parkfield earthquake might be caused by periodic stress discharges that occur at an increasing rate.

The spatial distribution of seismicity at Parkfield can thus be qualitatively described. Stress must concentrate in the creeping-locked transition zone, where the stably sliding (or "creeping") portion of the SAF to the north of Parkfield meets the unstable "locked" portion to the south (although in the rate-and-state description, this "locked" portion is considered to be slipping to a very small degree). This enhanced stress in the crust surrounding the creeping/locked intersection is likely to be the reason why the seismic activity is generally concentrated there.

However, the $30 \mathrm{~km}$ diameter zone surrounding the epicenter that exhibits low seismic activity in the year prior to the main event requires a more subtle explanation. The rocks to the southwest of the SAF, where this zone lies, contain granite and are generally stronger than the sedimentary rocks to the northeast; such heterogeneity, together with the intersection of the locked and creeping sections of the SAF, result in complex local stress patterns. Only numerical simulations can indicate whether the modeled stress concentrations are consistent with the observed spatial distribution of seismicity. Usually, the fault zones are subjected to a constant strain-change rate and have a long history of periodic slip, with the same maximum stress value and along the same orientation. As a result of such a cyclic stress load, most of the fractures that were overcritically stressed are now discharged, and application of the same loading conditions triggers few new events. It is common to assume that rock masses contain 
numerous critically stressed fractures with random locations and orientations. At the same time, the weak fault itself can be regarded as a large-scale fracture, with the fracture tip in the transition zone. Fracture-tip vicinities are known for generation of highest stresses under loading (Sholtz, 1990). While the locked and creeping sections of the fault zones show stress changes occurring primarily in the same direction, in the transition zones stress gradients are high, and stress changes lead to changes in the orientations of principal stresses. This creates new dimensions along which triggering of critically stressed fractures can occur and explains the previously described observation of increased seismicity in the transition zones.

The increased sharpness of seismicity peaks for small magnitude events can be explained by nonuniform station coverage in the region. Most of the stations (especially High Resolution Seismic Network (HRSN)) are concentrated along the southeast creeping part of the SAF, where the pre-event seismicity is concentrated. In other words, the spatial inhomogeneity of station coverage in this case correlates with the pattern of spatial inhomogeneity of the micro-events. Obviously, small-magnitude seismicity in this region has a higher chance of being detected, providing the observed intensity of the precursor.

Thurber et al. (2006) claim that “...differential times help sharpen the Vp image along the SAF and also resolve the seismicity streaks and multiplets reported previously in the double-difference location study of Waldhauser et al. (2004), ...”. Such impressive accuracy for relatively large (> $80 \mathrm{~km} 2$ ) seismicity count areas (Figures 4,8,and 10), and confinement of errors for absolute locations of the events within $1 \mathrm{~km}$ distance (Zhang and Thurber, 2003), justifies the robustness of the observed pre-event peaks. Somewhat surprisingly look the comparison of the average event location accuracy by USGS and DD. The same events from USGS and DD catalogs (19963 events in total) were used, where 19 events with rms > 1s were discarded as outliners. For the rest 19944 events the average rms value was computed as a function of the event magnitude. DD relocations gave improvement to $65 \%$ of events, but for the $35 \%$ of events rms values have increased. However, the average rms value for USGS locations is $0.0673 \mathrm{~s}$, while for DD locations the average rms $=0.0773 \mathrm{~s}$ which is by $15 \%$ less accurate. The average rms values as the functions of magnitude are plotted on Figure 13. USGS locations look slightly better than DD locations suggesting that while DD method seems to work well for correcting the relative locations, the absolute locations are not improved by application of this method. Notably, the location accuracy of small- 
magnitude events is better than for mid-range magnitudes in both cases, which justifies use of small-magnitude events in the seismicity analysis. Better location accuracy of small-magnitude events might be explained by increase of rapture length for events with larger magnitudes. To ensure data quality in the out-of-fault seismicity analysis the monthly average rms values were computed for the selection area from Figure 4. During last two years preceding M6 Parkfield earthquakes there is no anomalous rise of event location error is evident (Figure 14), which eliminates a hypothesis about possible artificial nature of precursory seismicity peaks as a result of migrated San Simeon M6.5 aftershock series.

Fault zone seismicity can be attributed to one of the four proposed seismicity types, which differ by their relationships with strain changes in and around the fault. First, there is the weak (creeping) fault seismicity, which results from steady strain release and represents the dominant fraction of all regional events. Seismicity of this type is not directly related to stress buildup in the locked portion of the fault. The second type of seismic behavior is related to areas around nucleation zones of the future earthquakes, where a decrease of seismicity is observed in pre-event stage. Such zones resemble Mogi doughnuts (Mogi, 1985), can have very elongated shapes, and are approximately equal in size to the future event rupture zone (Reasenberg and Simpson, 1992). The third type of seismicity corresponds to an aftershock series of moderate and large events, which may significantly contribute to the overall statistics but do not provide obvious clues for large earthquake prediction. The fourth type is the out-off-fault-zone seismicity occurring in the relatively intact rocks surrounding the fault zones. This type of seismicity is directly related to stress buildup in the crust and provides only a moderate number of detectable events, because these events are small. The results of this paper were mainly based on this fourth type of seismicity. The shape and size of the fourth seismicity type regions are likely to have a direct relationship to the magnitude of the future main event. The greater the portion of the fault bathed in the seismicity, the larger the area experiencing accelerated slip, with the subsequent possibility of a larger induced earthquake.

Because of the absence of other precursors (Bakun et al., 2005), the observed preevent peaks of seismicity reported here are especially important for use in earthquake prediction. The occurrence of these peaks several months in advance of the main event should allow special observation of future rupture zones to accurately estimate the 
earthquake striking time. Low pre-event seismicity levels in these zones require active monitoring that uses controlled seismic sources to observe changes within the fault zone associated with rock softening (Artamonova and Korneev, 2005). It seems natural that rock softening should affect seismic wave attenuation and velocities, although the physics that would allow modeling of such changes is not yet well understood.

The observed peak of seismic background noise before 1993-1994 M4 series (Figure 6) repeats the seismicity patterns of the M6 2004 Parkfield earthquake (Figure 2). If shown for large data volumes, this direct correspondence between seismicity and seismic noise level may provide a key method for making instantaneous measurements of seismicity (stress) and its changes.

\section{Conclusions}

Peaks in seismicity occurring several months prior to two recent SAF large events indicate that they are good candidates for earthquake prediction studies. Aftershocks and creeping fault seismic activity mask the effect and should be excluded from the data, as having little or no relation to the stress buildup in the locked fault zones. The size and location of earthquakes correspond to both the size and location of the "quiet" zones and the zones of increased seismicity occurring before the main shocks. Because of their frequent occurrence, small magnitude events may be ideal for routine daily monitoring of stress changes. The development of active seismic monitoring techniques is necessary for investigating changes in the pre-seismic nucleation zone. The observations reported here leave open the possibility that successful earthquake prediction may yet be possible.

\section{Acknowledgments}

Data processing was done at the Center for Computational Seismology (CCS) at Lawrence Berkeley National Laboratory, which is operated by the University of California for the U.S. Department of Energy (DOE) under Contract No. DE-AC03-76SF00098. The author thanks Federica Marone for supplying earthquake data, and also Robert Nadeau, who made several helpful comments. This paper significantly benefited from the help and suggestions of Steven Pride. Ruth Harris suggested to recompute the results using relocated events in Parkfield area, and Cliff Thurber kindly provided such yet unpublished data. 


\section{Bibliography}

Artamonova M.S. and V.A. Korneev, Active Seismic Monitoring for Earthquake Forecasting, Eos Trans. AGU, 86(52), Fall Meet. Suppl., Abstract NG32A-06, 2005.

Bakun, W.H. , B. Aagaard, B. Dost, W.L. Ellsworth, J.L. Hardebeck, R.A. Harris, C. Ji, M.J.S. Johnston, J. Langbein, J.J. Lienkaemper, A.J. Michael, J.R. Murray, R.M. Nadeau, P.A. Reasenberg, M.S. Reichle, E.A. Roeloffs, A. Shakal, R.W. Simpson and $F$. Waldhauser, Implications for prediction and hazard assessment from the 2004 Parkfield earthquake, Nature, doi: 10.1038/nature04067, 2005.

Bakun, W.H., and T.V. McEvilly, Earthquakes near Parkfield, California: Comparing the 1934 and 1966 Sequences, Science, 205, 1375-1377, 1979.

Bakun, W.H., and A.G. Lindh, The Parkfield, California, prediction experiment, Earthq. Predict. Res., 3, 285-304, 1985.

Bowman, D.D. and C.G. Sammis, Intermittent criticality and the Gutenberg-Richter distribution, Pure Appl. Geophys., 104, 1945-1956, doi:10.1007/s00024-004-2541-z, 2004.

Dieterich, J. A., A constitutive law for rate of earthquake production and its application to earthquake clustering, J. Geophys. Res., 99, 2601-2618, 1994.

Dunegan, H.L., Prediction of Earthquakes with AE/MS? Why not" 6th Conference on AE/MS Activity in Geologic Structures and Materials, Pennsylvania State University, June 1996.

Geller, R.J. Earthquake prediction: a critical review. Geophys. J. Int. 131, 425-450, 1997.

Geller, R.G., David D. Jackson, Yan Y. Kagan, and Francesco Mulargia, Earthquakes cannot be predicted. Science, 275 (5306), 1616, 1996.

Karageorgi, E., R. Clymer and T.V. McEvilly, Seismological studies at Parkfield: II. Search for temporal variations in wave propagation using Vibroseis, Bull. Seismol. Soc. Am., 82, 1388-1415, 1992.

Karageorgi, E.D., T.V. McEvilly, and R.W. Clymer, Seismological studies at Parkfield IV: Variations incontrolled-source waveform parameters and their correlation with seismic activity 1987-1994, Bull.Seism. Soc. Am., 1996.

Korneev, V.A., Seismicity precursors of M6.0 2004 Parkfield and M7.0 1989 Loma Prieta earthquakes, Eos Trans. AGU, 86 (52), Fall Meet. Suppl., Abstract S53B-1097, 2005.

Korneev, V.A., and R. Nadeau, Vibroseis Monitoring of San Andreas Fault in California, Proceedings of the International Workshop in Active Monitoring, Mizinami, 88-95. LBNL-55511 (707 KB), 2004.

Korneev, V.A., T.V. McEvilly, and E.D. Karageorgi, Seismological studies at Parkfield VIII: Modeling the observed travel-time changes, Bull. Seismol. Soc. Am., 90 (3), 702-708, 2000. 
Korneev, V.A., R.M. Nadeau, and T.V. McEvilly, Seismological studies at Parkfield IX: Fault zone imaging using guided wave attenuation, Bull. Seism. Soc. Am., 93 (4), 1415-1426, 2003.

Langbein, J., R. Borherdt, D. Dreger, J. Fletcher, J.L. Hardebeck, M. Hellweg, C. Ji, M. Johnston, J.R. Murray, R.N. Nadeau, M.J. Rymer, and J.A. Treiman, Preliminary report on the 29 September 2004, M 6.0 Park field, California earthquake, 2005,. Seismological Research Letters 76 (1), 10-26.

Lei, X.-L., K. Kusunose, O. Nishizawa, A. Cho, and T. Satoh, On the spatio-temporal distribution of acoustic emissions in two granitic rocks under triaxial compression: The role of pre-existing cracks, Geophys. Res. Lett., 27 (13) , 1997-2000, 2000.

Lei, X.-L., K. Kusunose, M.V.M.S. Rao, O. Nishizawa, and T. Satoh, Quasi-static fault growth and cracking in homogeneous brittle rocks under triaxial compression using acoustic emission monitoring, J. Geophys. Res., 105 (B3), 6127-6139, 2000.

Lei, X.-L., K. Masuda, O. Nishizawa, L. Jouniaux, L. Liu, W. Ma, T. Satoh, K. Kusunose, Detailed analysis of acoustic emission activity during catastrophic fracture of faults in rocks, J. Struct. Geol., 26, 247-258, 2004.

Lei, X.-L. , T. Satoh, O. Nishizawa, K. Kusunose, M.V.M.S. Rao, Modeling damage creation in stressed brittle rocks by means of acoustic emission, Proceedings of the 6th International Symposium on Rockbursts and Seismicity in Mines (RsSim6), Australia, 327-334, 2005.

Lockner, D.A., J. Byerlee, V. Kusenko, A. Ponomarev, and A. Sidorin, Observations of quasistatic fault growth from acoustic emissions, in Fault Mechanics and Transport Properties of Rocks, B. Evans and T.-F Wong, eds., pp. 3-31, Academic Press, London, 1992.

Melosh, H.J., Acoustic fluidization: A new geologic process? JGR, 84, 7513-7520, 1979. Mogi, K., 1985. Earthquake Prediction. Academic Press, Tokyo. Japan, 1985.

Meltzner, A.J., and D.J. Wald, Foreshocks and aftershocks of the great 1857 California earthquake, Bull. Seism. Soc. Am., 89, 1109-1120, 1999.

Reasenberg, P.A., and R.W. Simpson, Response of regional seismicity to the static stress change by the Loma Prieta earthquake, Science, 255, 1687-1690, 1992.

Ruina, A.L. Slip instability and state variable-friction laws, J. Geophys. Res., 88, 1035910370, 1983.

Scholz, C.H., The Mechanics of Earthquakes and Faulting, Cambridge University Press, 1990.

Sobolev, G.A., O.V. Babichev, V.F. Los,.A.V. Kol'tsov,A.V. Ponomaryov, V.I. Ponyatovskaya, A.S. Rozanov, S.A. Stanchits, A.A. Khromov, D.I. Frolov, L. Yangquan, Z. Jialiu, Q. Jiadong, and L. Shiyu, Precursors of the destruction of water containing blocks of rock., J. Earthquake Prediction Research, 39,1996.

Tham, L.G., Y.K. Cheung, and C.A. Tang, Numerical simulation of the failure process of rocks, Tamkang Journal of Science and Engineering, 4 (4), 239-252 (2001).

Thurber, C., Zhang, H., Waldhauser, F., Hardebeck, J., Michael, A., and , D.

Eberhart-Phillips, Three-Dimensional Compressional Wavespeed Model, Earthquake

Relocations, and Focal Mechanisms for the Parkfield, California, Region, (Bull. Seism.

Soc. Am , This issue), 2006.

Wald, D.J., H.V. Kanamori, D.V. Helmberger, and T.H. Heaton, Source study of the 1906 San Francisco Earthquake, Bull. Seism. Soc. Am., 83, 981-1019, 1993.

Zhang, H. and C. H. Thurber, Double-Difference Tomography: The Method and Its Application to the Hayward Fault, California, Bull. Seism. Soc. Am., 83, vol. 93; no. 5; p. 1875-1889; DOI: 10.1785/0120020190, 2003. 
Valeri Korneev,

90-1116, ESD, 1 Cyclotron Rd, Lawrence

Berkeley National Laboratory, Berkeley, CA

94720, USA;: VAKorneev@lbl.gov 


\section{Figure captions}

Figure 1. Cumulative seismicity vs magnitude for Parkfield area using all events from 1968 till M6 2004 main shock on September 28. Straight dashed line shows GRR fit. Deviation from GRR is visible for magnitudes less than 1.5.

Figure 2. Seismicity of the SAF at Parkfield area during 36 years before M6.0 September 28, 2004 earthquake. Partially shown the topographic map of Parkfield area. Red dots are the event epicenters. Dashed green lines are the bounds of excluded corridor around SAF. Dashed blue line is delineation zone (Korneev et al. 2003) between locked and creeping parts of SAF. Yellow square marks the epicenter of the M6.0 event.

Figure 3. Seismicity of the SAF at Parkfield area (shown on Figure 2) during 36 years before M6.0 September 28, 2004 earthquake. Note the steady seismicity rise starting at year 2000. Visible seismicity peaks correspond to the aftershock series following the M5.5 1975 Parkfield, M6.5 1983 Coalinga, and a series of four M4 1992-1994 Parkfield events.

Figure 4. Seismicity of the SAF at Parkfield area from 1968 till M6.0 September 28, 2004 earthquake which was used in the analysis. Fault zone events within $6 \mathrm{~km}$ and outside of $15 \mathrm{~km}$ corridors around the SAF trace are excluded. Partially shown the topographic map of Parkfield area. Red dots are the event epicenters. Dashed green lines are the bounds of excluded corridor around SAF. Yellow square marks the epicenter of the M6.0 event.

Figure 5. Average number of events per month at Parkfield area before M6.0 September 28, 2004 earthquake. (a) All events starting from 1968. The 1970 and 1983 spikes are correspondently post seismic aftershocks of M4 SAF and M6.5 Coalinga events. (b) Average number of events per 10 days starting from 2000. Visible are cyclic bursts of seismicity with decreasing intervals between peaks as time approaches the 
earthquake. (c) Small $(M<1)$ magnitude events of the same series as on a). (d) Average number of $M<1$ events per 10 days starting from 2000. The seismicity peak is reached 6 months before the earthquake followed by steady decrease.

Figure 6 Seismicity of SAF at Parkfield area during 1 year before M6.0 September 28, 2004 earthquake. Fault zone events within $6 \mathrm{~km}$ and outside of $15 \mathrm{~km}$ corridors around the SAF trace are excluded. Note the "quiet" zone around the locked part. Most of the pre-event seismicity takes place in the vicinity of the creeping-locked delineation zone.

Figure 7. Central California topographic map (www.usgs.gov) and its seismicity. Two scan-stripes crossing SAF at Parkfield and Loma Prieta areas were used for computations of seismicity history shown correspondingly on Figures 8 and 10 . Parkfield scan-stripe crosses epicentral regions of M6.5 San Simeon 2003 on the southwest flank and of M6.5 Coalinga 1983 on the north-east flank. Center of this scan stripe crosses Parkfield area along delineation zone shown on Figure 2 by dashed blue line. Loma Prieta scan-stripe crosses Calaveras fault on the north-east flank.

Figure 8. Seismicity history for $4 \mathrm{~km}$ by $20 \mathrm{~km}$ rectangular scanning along the scanstripe from Figure 7 in southeast-northwest direction. The longest side of the rectangular is parallel to SAF. The offset has values in $-80 \mathrm{~km}-60 \mathrm{~km}$ range and measured from the SAF with $4 \mathrm{~km}$ interval, ensuring that no event is counted more then once. (a) Data for the 1968-2005 interval. Visible are bursts of seismicity correspondent to M6.5 2003 San Simeon (-60km offset) and 1983 M6.5 Coalinga (37 km offset). The circles area shows the only in 38 years of observation burst of out-of-fault seismicity preceding M6.0 Parkfield earthquake. (b) Blow-up of the last three years from (a). Upper circle contains seismicity preceding M6 Parkfield event. The lower circle shows a similar seismicity pattern for M4.2 Parkfield 2002 event. In both cases the rise of seismicity starts 5-7 months before the main event at about 10-15 km offsets from SAF, 
and gradually moving closer (5 $\mathrm{km}$ offset) to the SAF couple months before the earthquake.

Figure 9 Seismicity of SAF at westerly Loma Prieta area before M7.0 October 17 earthquake. a) Red dots are the event epicenters. Green line indicates SAF trace. b) Same as on previous panel when just the events of the last year are plotted. Note the "quiet" zone on southwest of the SAF, which is similar to that on Figure 6) Average number of earthquakes per month starting from 1968. d) Average number of earthquakes per 10 days starting from 1987. The seismicity peak is reached 2 months before the earthquake followed by steady decrease.

Figure 10 Seismicity history for $4 \mathrm{~km}$ by $20 \mathrm{~km}$ rectangular scanning in southeast northwest direction across the M7 Loma Prieta epicenter: (a) 1970-1990 time interval; (b) Blow-up of the last three years from (a). The geometry of the scan-stripe is shown on Figure 7. The longest side of the rectangular is parallel to SAF. The offset has values in $-45 \mathrm{~km}-80 \mathrm{~km}$ range and measured from the SAF with $4 \mathrm{~km}$ interval, ensuring that no event is counted more then once. Red circle contains seismicity growth preceding M7 Loma Prieta event. Note that M5.3 1988 event gave just a slight rise of seismicity (Figure 9d) while M5.4 1989 event was preceded by distinctive seismicity outbursts with together with this event gave pre- M7 peak. This pre-event seismicity pattern is similar to the pattern observed for M6 Parkfield earthquake from Figure 8.

Figure 11 Seismic noise at $80 \mathrm{~Hz}$ (solid line) and released seismic energy (dashed line) for MMNB station at SAF. Energy is computed within $5 \mathrm{~km}$ radius from MMNB location using 1 year averaging window. Seismic noise peak occurs about 6 months before the energy peak, which is related to 1993-1994 M4 series at Parkfield. Note the repeat of this pattern with peak of noise at the middle of 1996 and the subsequent peak in energy in the early 1997.

Figure 12 (a) Stress-strain curves for weak fault rock (red curve) and stronger out-offault rock (blue curve). Stress changes over time for both rocks are the same. For an increasing strain, the stress in the fault material becomes nonlinear and reaches a maximum, entering a dilatancy zone characterized by development of multiple fractures and reduction of rock stiffness, and eventually progressing to the failure point $F$. At the 
same time, the stronger out-of-fault rock experiences linear changes reaching maximum strain at Point $C$ and then decreasing to Point $L$ at the failure time. (b) Seismicity history computed from stress history (shown in upper panel) using fourth-power law (Dunegan, 1999), which provides a qualitative explanation for the observed precursory peaks.

Figure 13. Average rms value vs magnitude for USGS and DD (Thurber et al., 2006) relocated events in Parkfield area. Note, that the largest location errors belong to 2-4 magnitude interval.

Figure 14. Monthly average rms values for events in the selection area from Figure 4. During last two years preceding M6 Parkfield earthquakes there is no anomalous rise of event location error, which eliminates hypothesis about artificial nature of precursory seismicity peaks. 


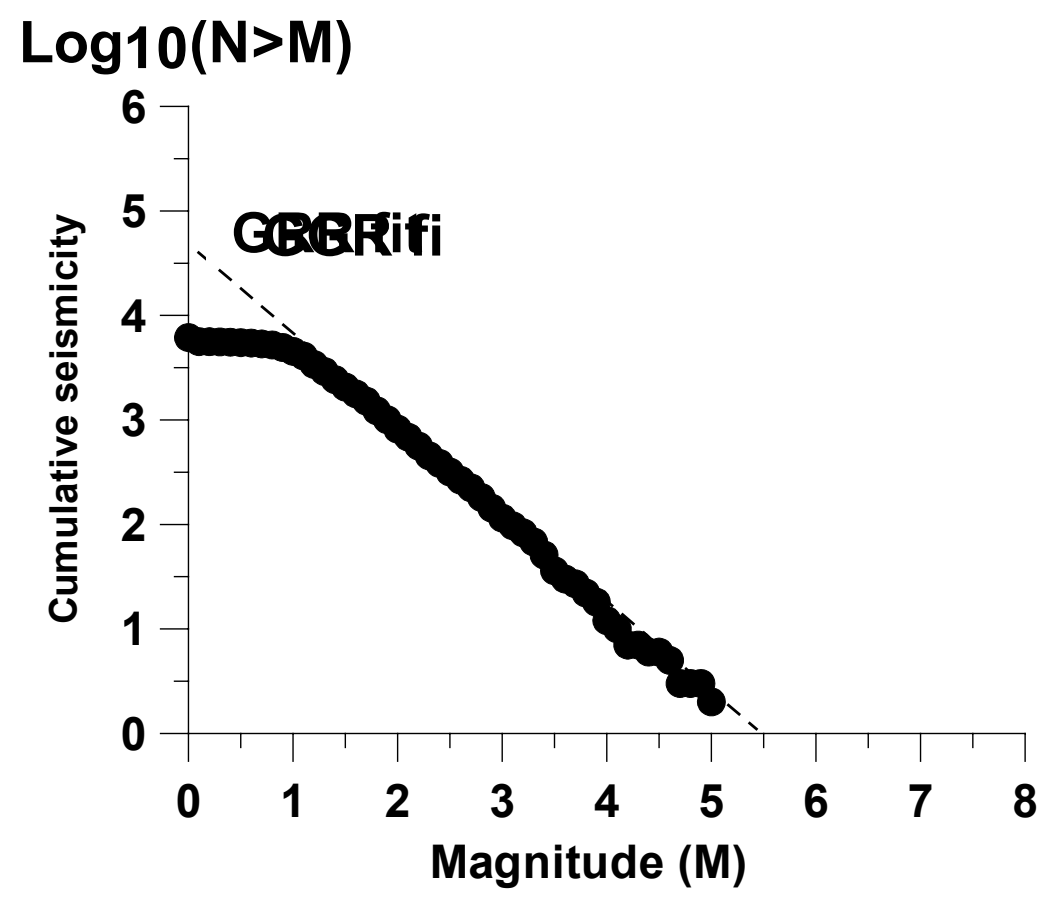

Figure 1. Cumulative seismicity vs magnitude for Parkfield area using all events from 1968 till M6 2004 main shock on September 28. Straight dashed line shows GRR fit. Deviation from GRR is visible for magnitudes less than 1.5. 


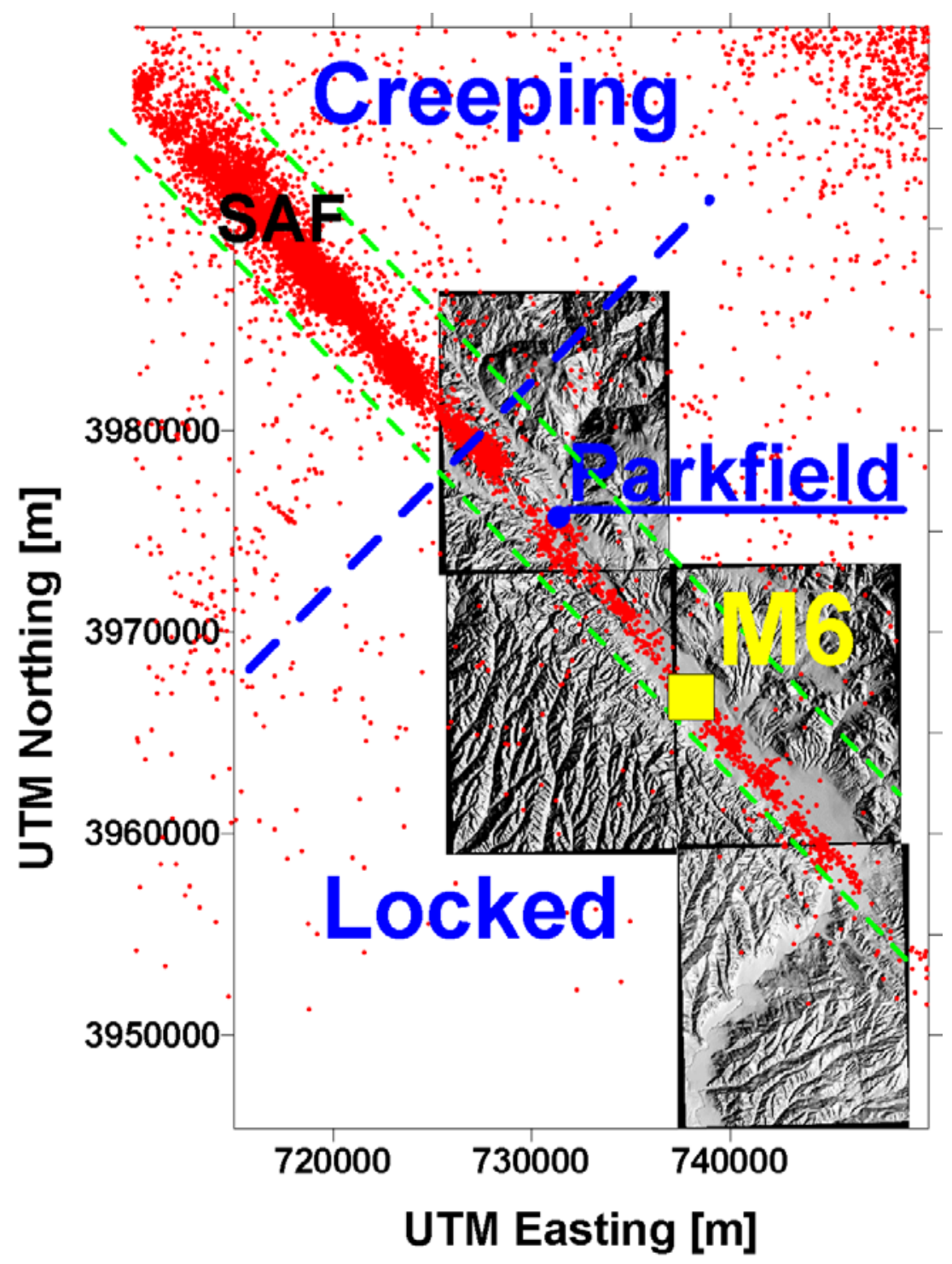

Figure 2. Seismicity of the SAF at Parkfield area during 36 years before M6.0 September 28, 2004 earthquake. Partially shown the topographic map of Parkfield area. Red dots are the event epicenters. Dashed green lines are the bounds of excluded corridor around SAF. Dashed blue line is delineation zone (Korneev et al. 2003) between locked and creeping parts of SAF. Yellow square marks the epicenter of the M6.0 event. 


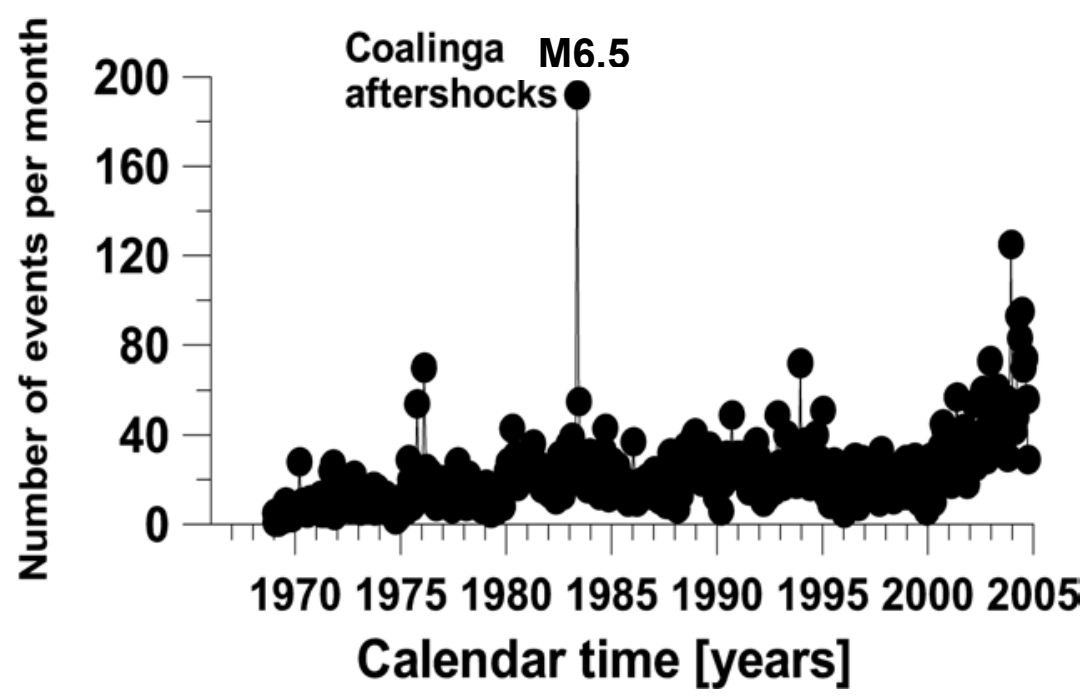

Figure 3. Seismicity of the SAF at Parkfield area (shown on Figure 2) during 36 years before M6.0 September 28, 2004 earthquake. Note the steady seismicity rise starting at year 2000. Visible seismicity peaks correspond to the aftershock series following the M5.5 1975 Parkfield, M6.5 1983 Coalinga, and a series of four M4 1992-1994 Parkfield events. 


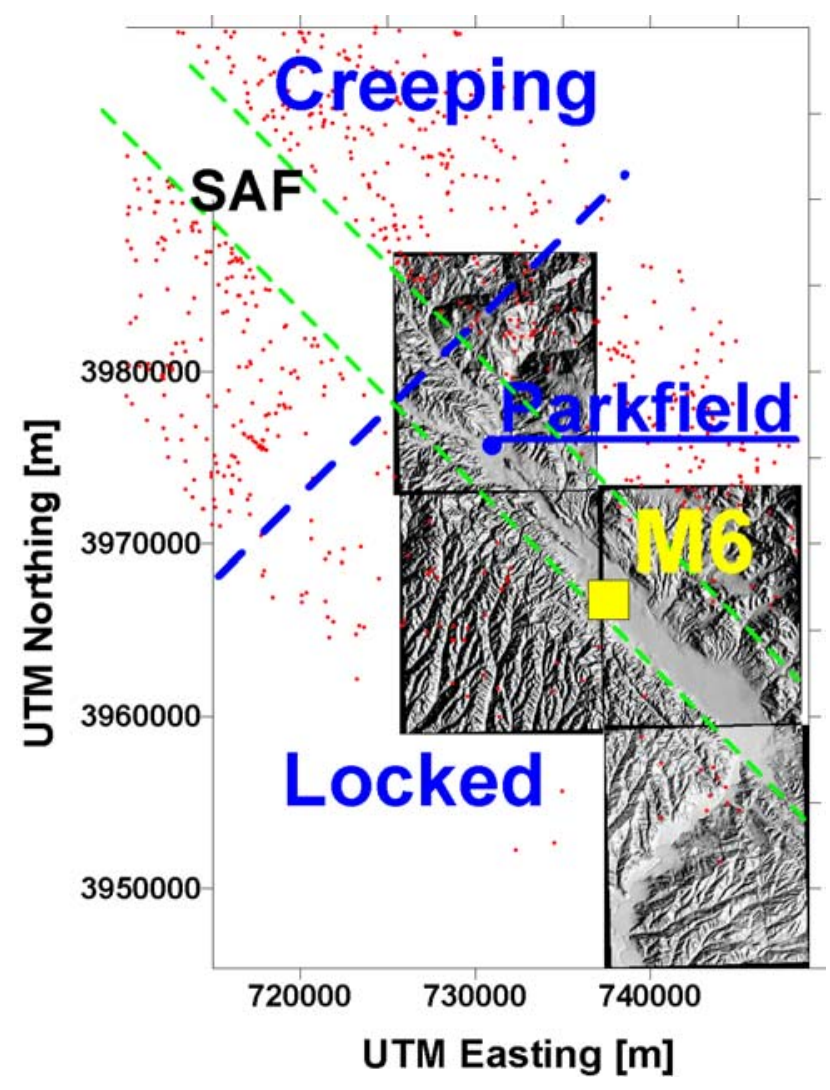

Figure 4. Seismicity of the SAF at Parkfield area from 1968 till M6.0 September 28, 2004 earthquake which was used in the analysis. Fault zone events within $6 \mathrm{~km}$ and outside of $15 \mathrm{~km}$ corridors around the SAF trace are excluded. Partially shown the topographic map of Parkfield area. Red dots are the event epicenters. Dashed green lines are the bounds of excluded corridor around SAF. Yellow square marks the epicenter of the M6.0 event. 
(a)

(c)

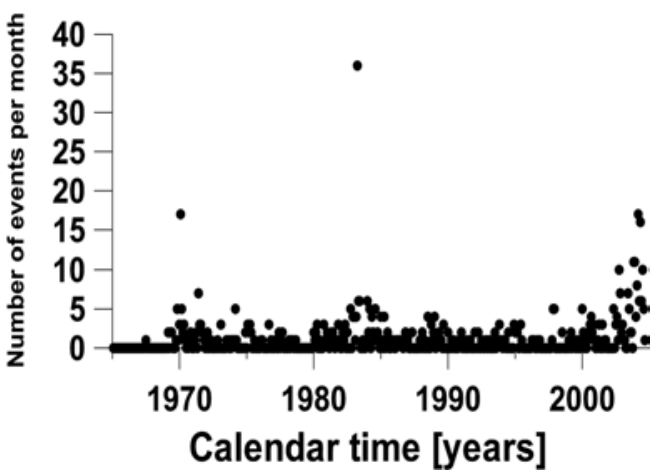

(b)

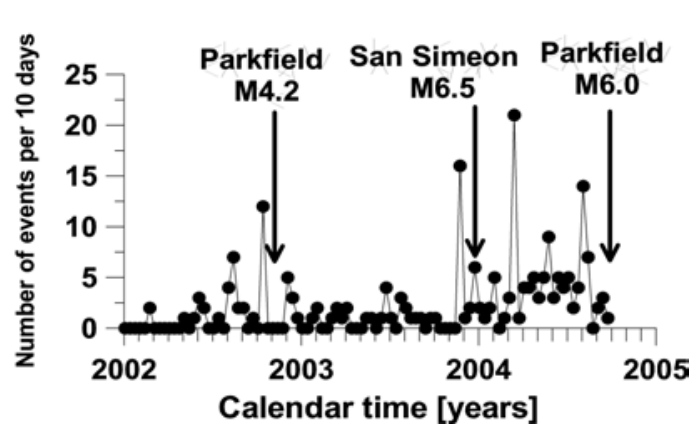

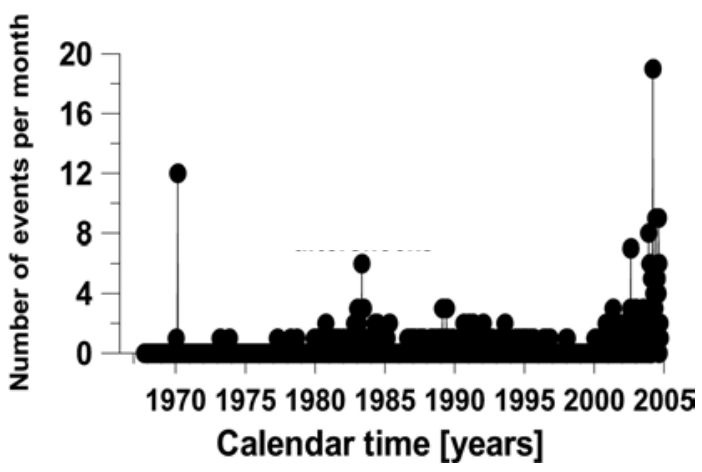

(d)

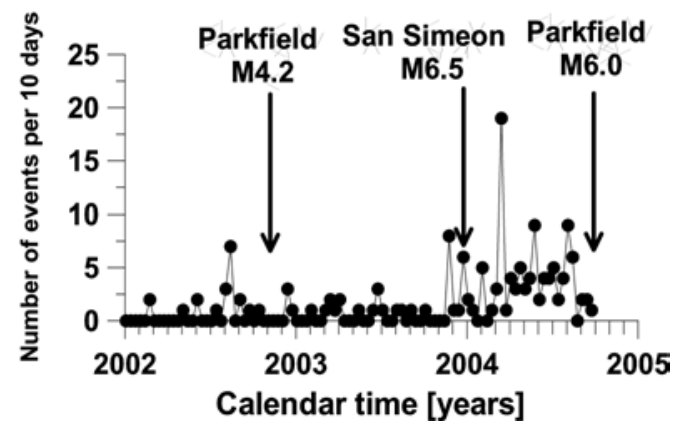

Figure 5. Average number of events per month at Parkfield area before M6.0 September 28, 2004 earthquake. (a) All events starting from 1968. The 1970 and 1983 spikes are correspondently post seismic aftershocks of M4 SAF and M6.5 Coalinga events. (b) Average number of events per 10 days starting from 2000. Visible are cyclic bursts of seismicity with decreasing intervals between peaks as time approaches the earthquake. (c) Small $(M<1)$ magnitude events of the same series as on a). (d) Average number of $M<1$ events per 10 days starting from 2000. The seismicity peak is reached 6 months before the earthquake followed by steady decrease. 


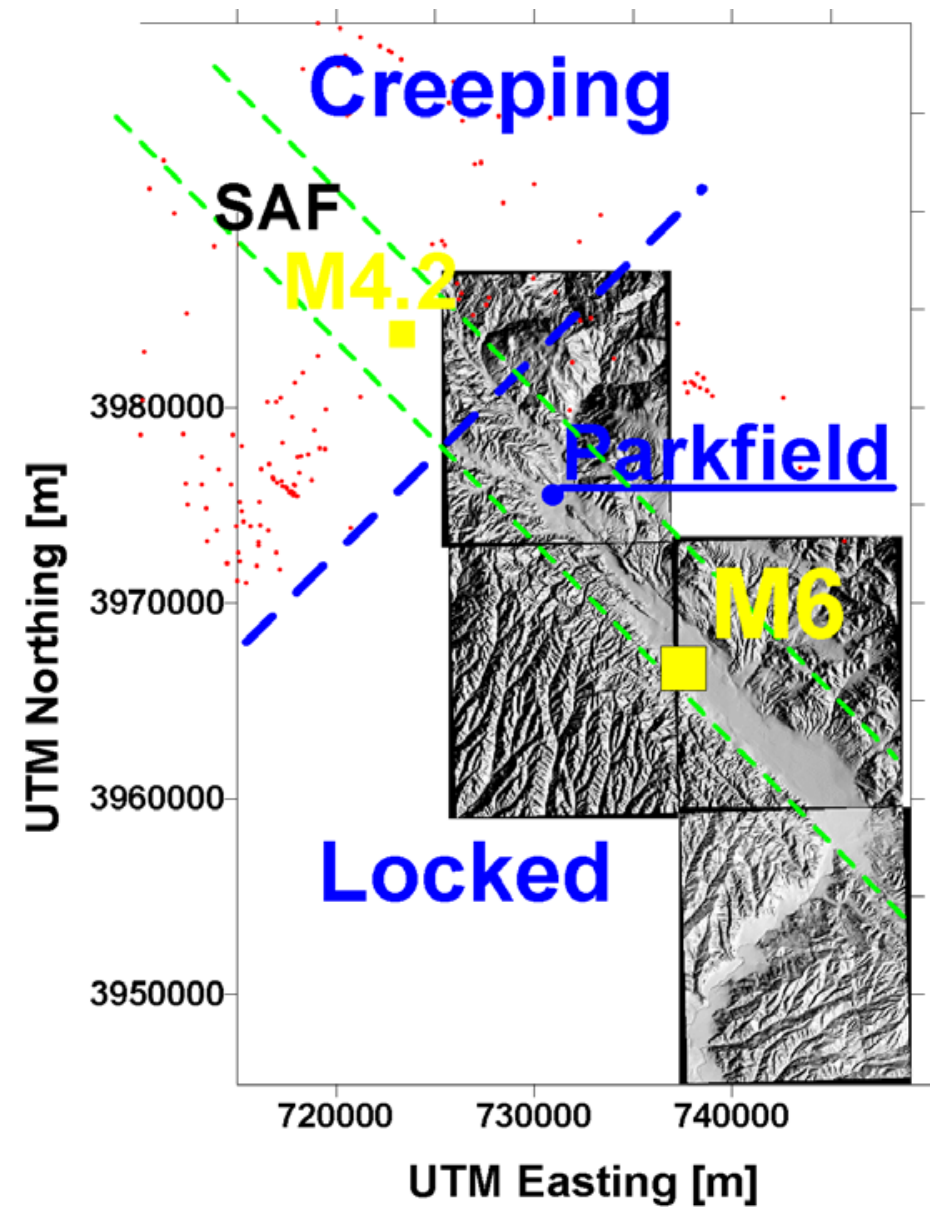

Figure 6 Seismicity of SAF at Parkfield area during 1 year before M6.0 September 28, 2004 earthquake. Fault zone events within $6 \mathrm{~km}$ and outside of $15 \mathrm{~km}$ corridors around the SAF trace are excluded. Note the "quiet" zone around the locked part. Most of the pre-event seismicity takes place in the vicinity of the creeping-locked delineation zone. 


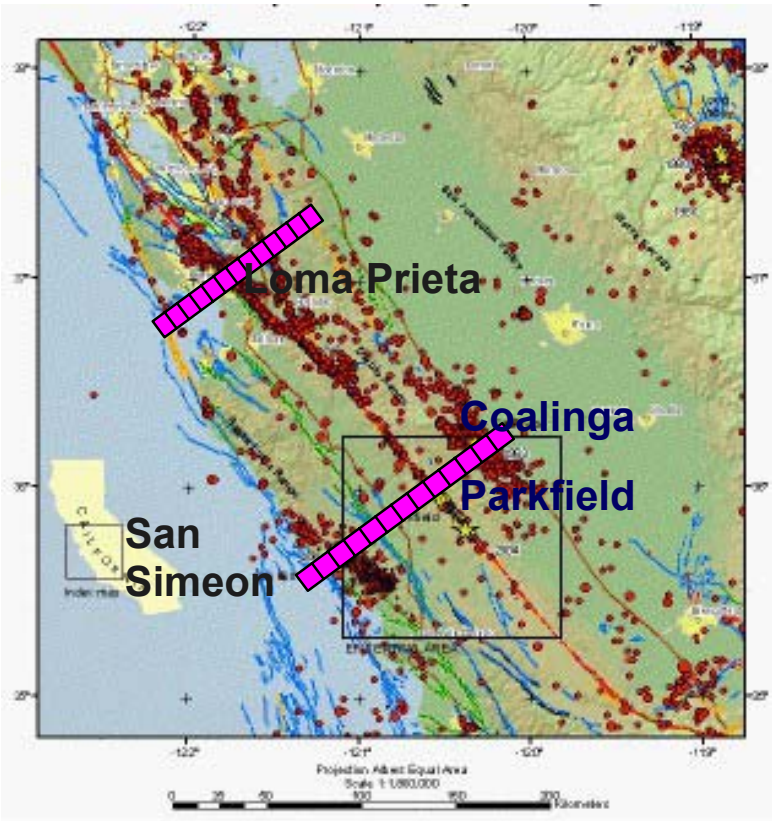

Figure 7. Central California topographic map (www.usgs.gov) and its seismicity. Two scan-stripes crossing SAF at Parkfield and Loma Prieta areas were used for computations of seismicity history shown correspondingly on Figures 8 and 10 . Parkfield scan-stripe crosses epicentral regions of M6.5 San Simeon 2003 on the southwest flank and of M6.5 Coalinga 1983 on the north-east flank. Center of this scan stripe crosses Parkfield area along delineation zone shown on Figure 2 by dashed blue line. Loma Prieta scan-stripe crosses Calaveras fault on the north-east flank. 


\section{(a)}

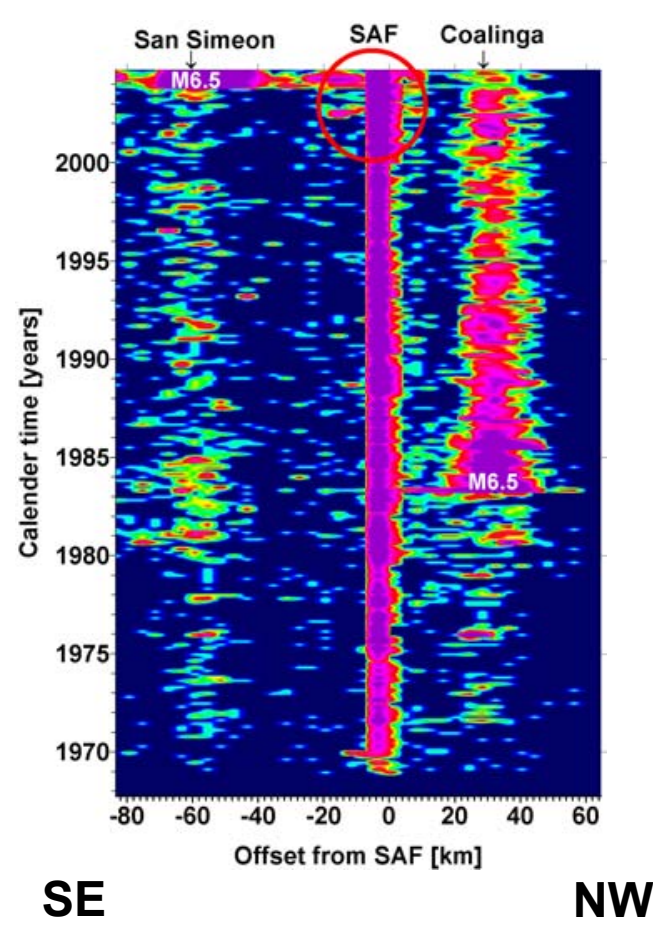

(b)

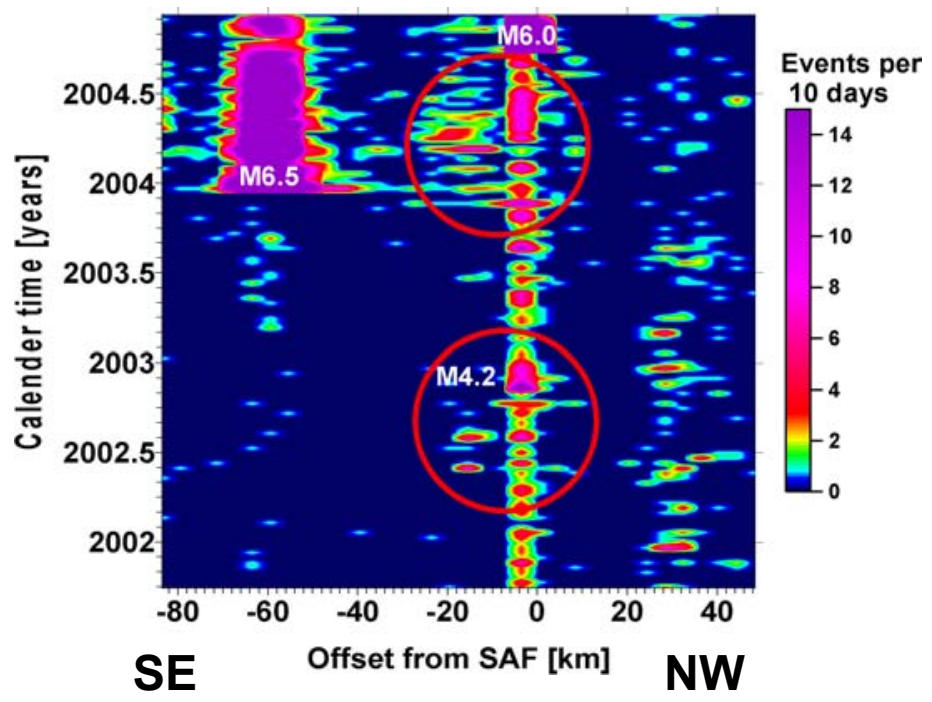

Figure 8. Seismicity history for $4 \mathrm{~km}$ by $20 \mathrm{~km}$ rectangular scanning along the scanstripe from Figure 7 in southeast-northwest direction. The longest side of the rectangular is parallel to SAF. The offset has values in $-80 \mathrm{~km}-60 \mathrm{~km}$ range and measured from the SAF with $4 \mathrm{~km}$ interval, ensuring that no event is counted more then once. (a) Data for the 1968-2005 interval. Visible are bursts of seismicity correspondent to M6.5 2003 San Simeon (-60km offset) and 1983 M6.5 Coalinga (37 km offset). The circles area shows the only in 38 years of observation burst of out-of-fault seismicity preceding M6.0 Parkfield earthquake. (b) Blow-up of the last three years from (a). Upper circle contains seismicity preceding M6 Parkfield event. The lower circle shows a similar seismicity pattern for M4.2 Parkfield 2002 event. In both cases the rise of seismicity starts 5-7 months before the main event at about 10-15 km offsets from SAF, and gradually moving closer (5 $\mathrm{km}$ offset) to the SAF couple months before the earthquake. 
(a)



(c)

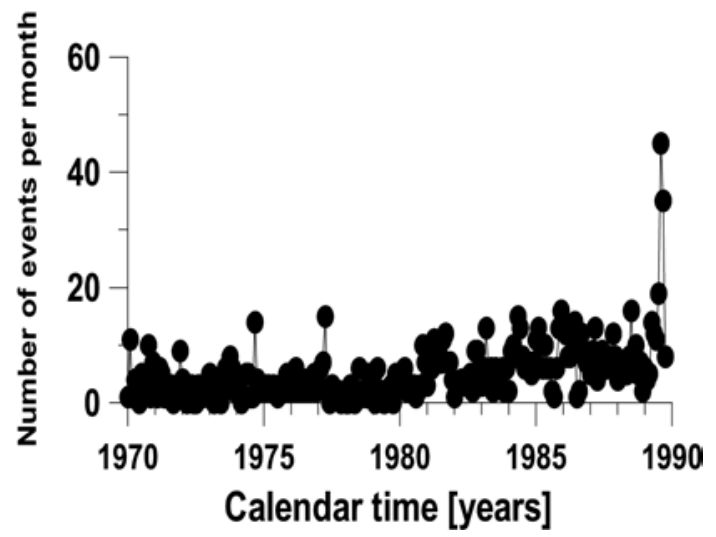

(b)

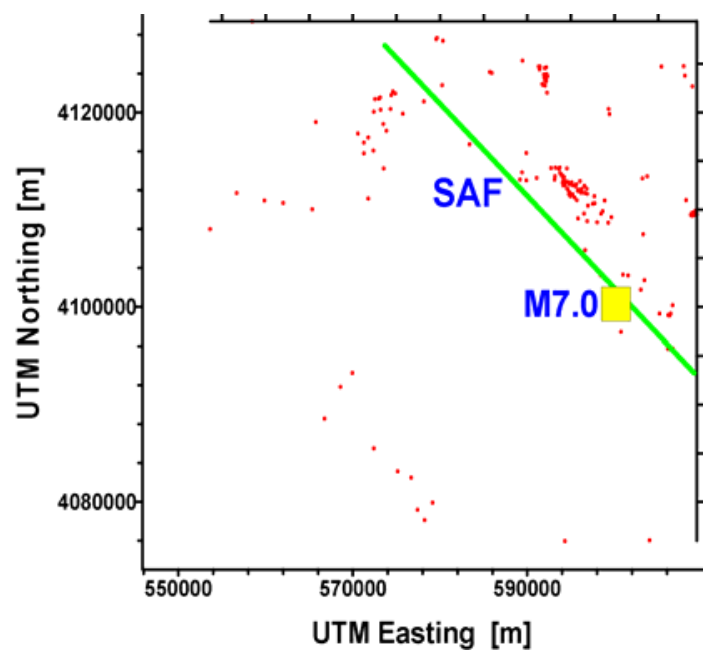

(d)

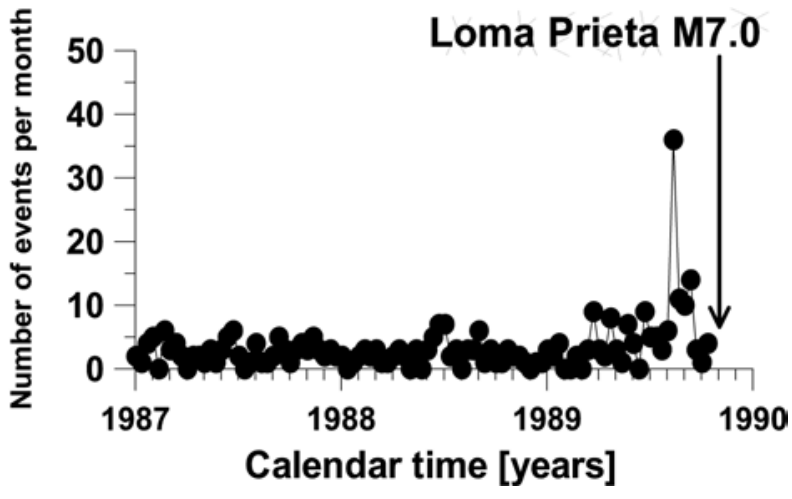

Figure 9. Seismicity of SAF at westerly Loma Prieta area before M7.0 October 17 earthquake. a) Red dots are the event epicenters. Green line indicates SAF trace. b) Same as on previous panel when just the events of the last year are plotted. Note the "quiet" zone on southwest of the SAF, which is similar to that on Figure 6) Average number of earthquakes per month starting from 1968. d) Average number of earthquakes per 10 days starting from 1987 . The seismicity peak is reached 2 months before the earthquake followed by steady decrease. 
(a)

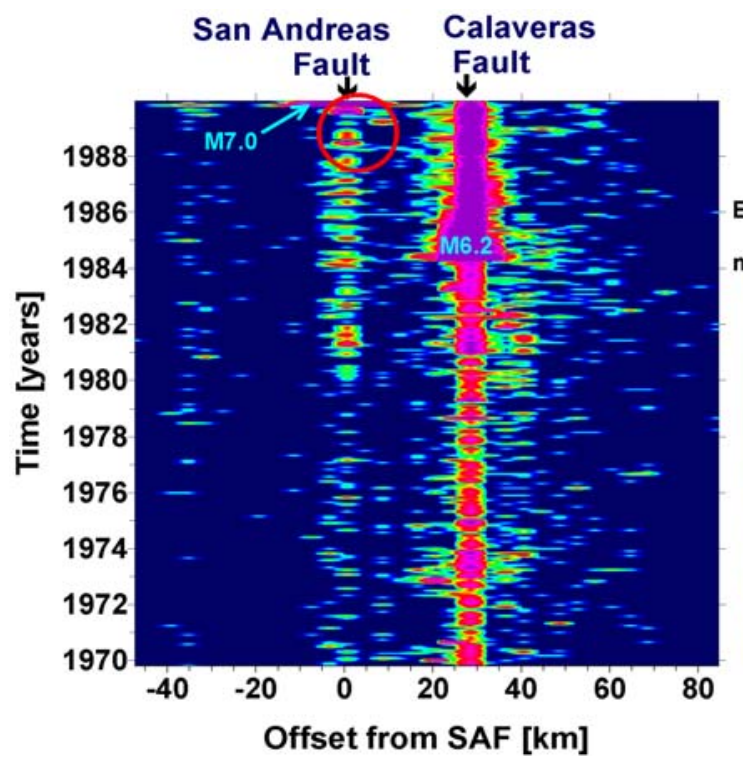

SE

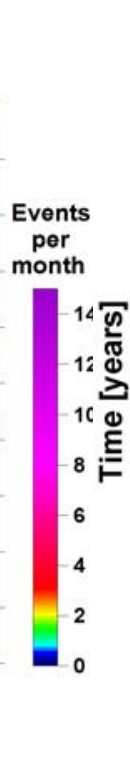

NW (b)

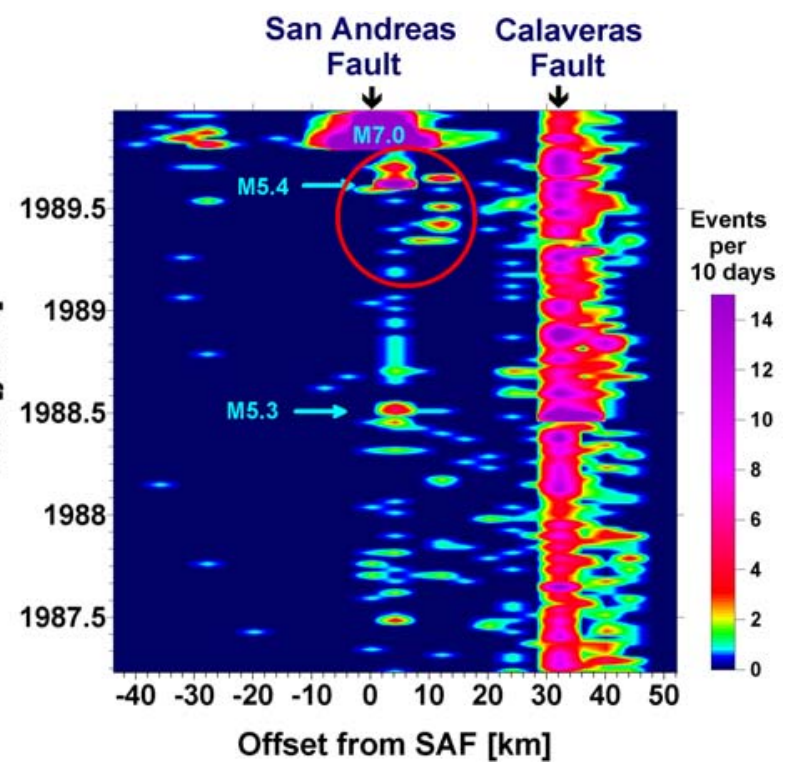

SE

Figure 10. Seismicity history for $4 \mathrm{~km}$ by $20 \mathrm{~km}$ rectangular scanning in southeast northwest direction across the M7 Loma Prieta epicenter: (a) 1970-1990 time interval; (b) Blow-up of the last three years from (a). The geometry of the scan-stripe is shown on Figure 7. The longest side of the rectangular is parallel to SAF. The offset has values in $-45 \mathrm{~km}-80 \mathrm{~km}$ range and measured from the SAF with $4 \mathrm{~km}$ interval, ensuring that no event is counted more then once. Red circle contains seismicity growth preceding M7 Loma Prieta event. Note that M5.3 1988 event gave just a slight rise of seismicity (Figure 9d) while M5.4 1989 event was preceded by distinctive seismicity outbursts with together with this event gave pre- M7 peak. This pre-event seismicity pattern is similar to the pattern observed for M6 Parkfield earthquake from Figure 8. 


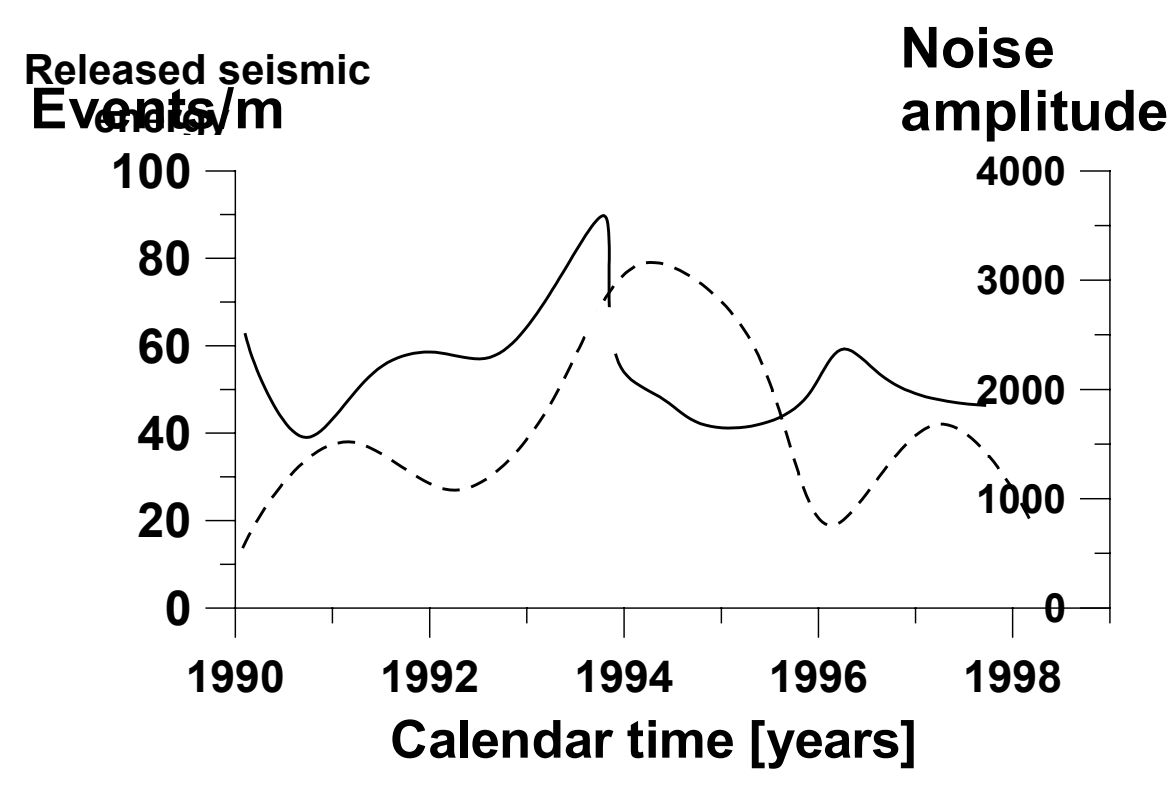

Figure 11 Seismic noise at $80 \mathrm{~Hz}$ (solid line) and released seismic energy (dashed line) for MMNB station at SAF. Energy is computed within $5 \mathrm{~km}$ radius from MMNB location using 1 year averaging window. Seismic noise peak occurs about 6 months before the energy peak, which is related to 1993-1994 M4 series at Parkfield. Note the repeat of this pattern with peak of noise at the middle of 1996 and the subsequent peak in energy in the early 1997. 
(a)

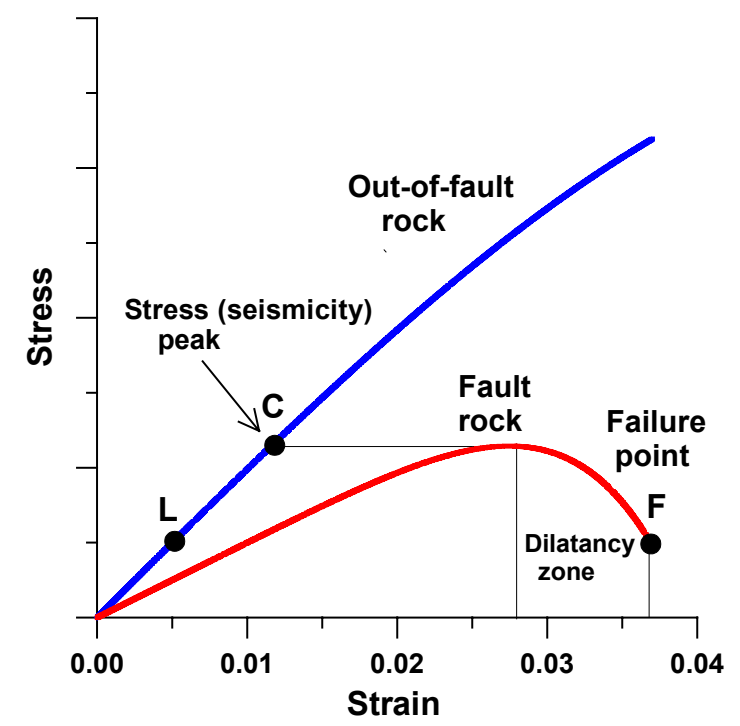

(b)

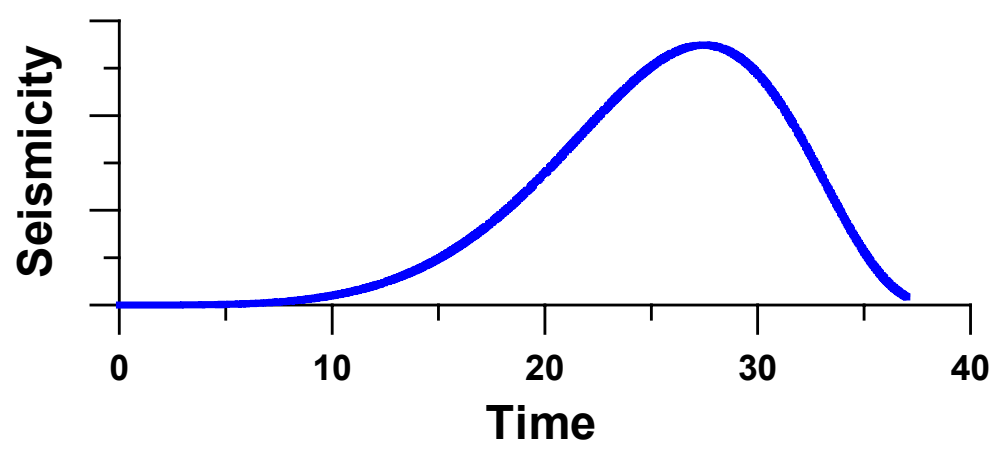

Figure 12. (a) Stress-strain curves for weak fault rock (red curve) and stronger out of fault rock (blue curve). Stress changes in time for both rocks are the same. For an increasing strain the stress in the fault material goes nonlinear and reaches a maximum entering a dilatancy zone which is characterized by development of multiple fractures and reduction of rock stiffness eventually progressing to the failure point $F$. At the same time the stronger out-of-fault rock experiences linear changes reaching maximum strain at point $C$ and decreasing to the point $L$ at the failure time.

(b) Seismicity history computed from stress history (shown on upper panel) using forth power law (Dunegan, 1999) gives qualitative explanation for the observed precursory peaks. 


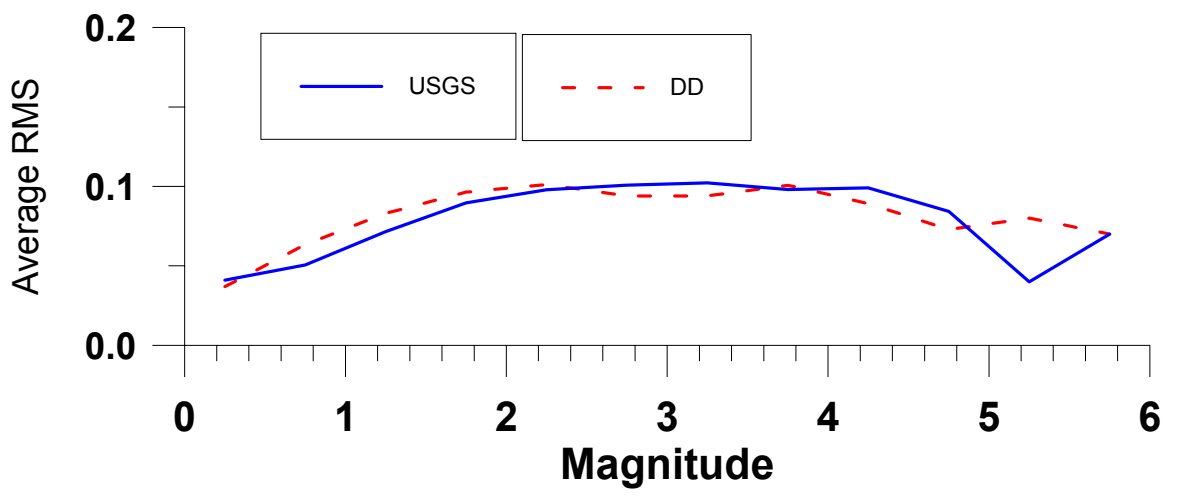

Figure 13. Average rms value vs magnitude for USGS and DD (Thurber et al., 2006) relocated events in Parkfield area. Note, that the largest location errors belong to 2-4 magnitude interval. 


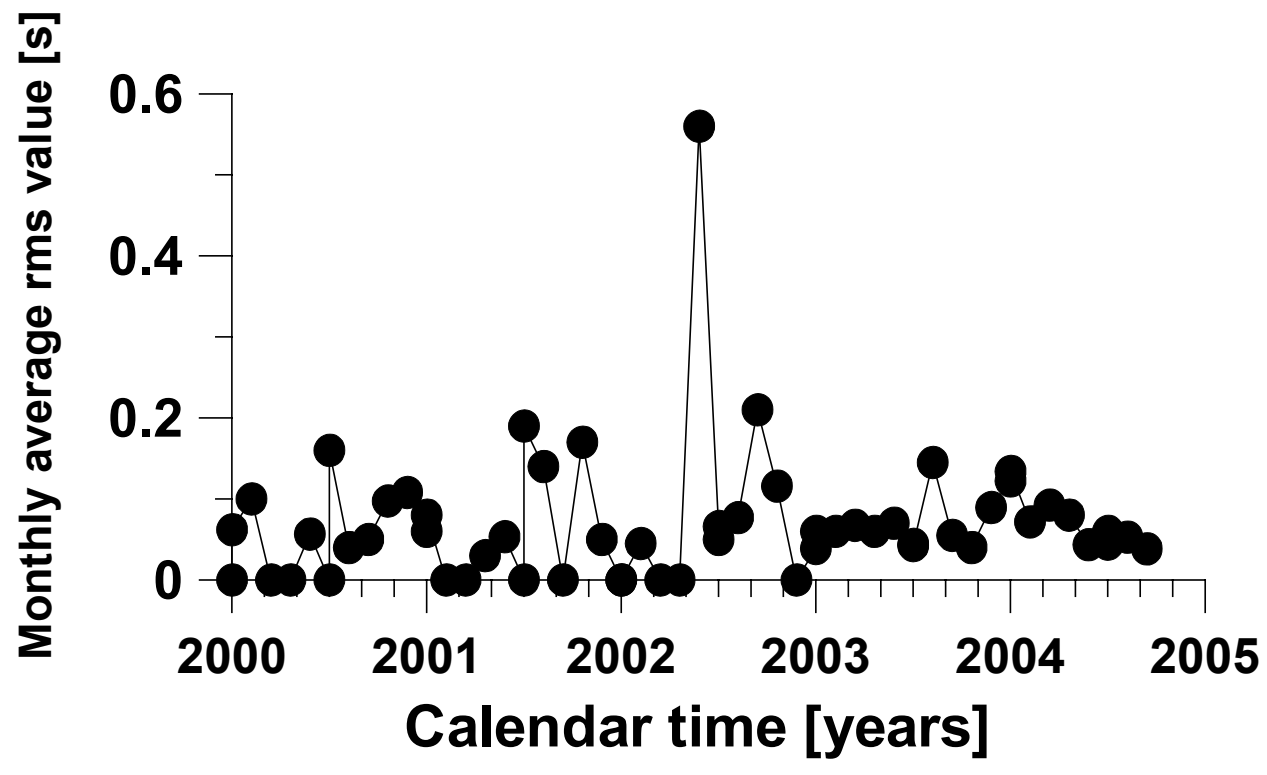

Figure 14. Monthly average rms values for events in the selection area from Figure 4. During last two years preceding M6 Parkfield earthquakes there is no anomalous rise of event location error, which eliminates hypothesis about artificial nature of precursory seismicity peaks. 